\title{
From "AIIB" to "the Belt and Road": the New Reform and Opening-up and "Top-down Design" under the Background of "New Normal" \\ --- Based on the Gradient Theory and the Theory of Comparative Advantage
}

\author{
Jie Gao, Yun-long Ding \\ Scool of Management Harbin Institute of Technology, Heilongjiang Province, China
}

\begin{abstract}
The purpose of this paper attempts to use the gradient theory and comparative advantage theory to analyze the AIIB and "the Belt and Road" strategy, to prove that these are the best strategic choice under the background of Chinese economic "new normal". The paper performs a comparative analysis based on the Asia Infrastructure Investment Bank, World Bank, Asian Development Bank and New Development Bank(BRICs), and also on the traditional reform and opening-up, western China development, and the new reform and opening-up with "the Belt and Road". In advancing the Belt and Road Initiative, China will fully leverage the comparative advantages of its various regions, adopt a proactive strategy of further opening-up, strengthen interaction and cooperation among the eastern, western and central regions, and comprehensively improve the openness of the Chinese economy. The findings could be helpful to understand the impact of AIIB and "the Belt and Road". The paper emphasizes Chinese new gradient transfer and comparative advantages with AIIB, "the Belt and Road" and other strategies, which will help China to go through the "new normal" stably, across the middle income trap, become powerful and innovative, and develop in collaboration with other countries.
\end{abstract}

Index Terms - AIIB, the Belt and Road, gradient transfer, comparative advantage, reform and opening-up.

\section{Introduction}

With a long time of rapid development, Chinese economy casting a "miracle" has been an important part of the great rejuvenation of the Chinese nation. But with the decrease of GDP growth rate, increasing downward pressure on the economy, various problems have emerged. The traditional comparative advantage of Chinese economy is no longer obvious. The gap between the East and West is widening, and western development and gradient transfer are negative. In difficult times, policymakers realize that although the economic growth slows down, its rate is still at a reasonable interval, and then continue to take a diametrically opposite approach through analysis and research, the most important challenge and problem to the current China's economy is the "three period superimposed" (1.Growth rate shift period, is decided by the objective laws of economic development institute; 2.Structural adjustment pains period, is the active choice of speeding up the transformation of economic development mode; 3.Stimulus policy digestion period, is a necessary stage to resolve the deep-seated contradictions accumulated over the years ). In order to make full use of the comparative advantage (such as excess capacity and capital output) and gradient transfer (such as new and all-round reform and opening-up), Chinese government creatively puts forward the establishment of AIIB and "the Belt and Road" strategy. In March 2015, "Vision and Actions on Jointly Building Silk Road Economic Belt and 21st-Century Maritime Silk Road" was issued by the National Development and Reform Commission, Ministry of Foreign Affairs, and Ministry of Commerce of the People's Republic of China, with State Council authorization. The new reform and opening-up and "top-down design" under the background of Chinese economic "new normal" started to implement.

\section{The Gradient Transfer Theory and the Theory of Comparative Advantage}

In the early or narrow gradient theory, economic and technological development level in the world, each country and region is not balanced, and there is a certain gradient, which needs transfer of new technologies, new productivity and other elements from high gradient area to low gradient area. And the gradient transfer will lead to the development of less developed areas gradually.

In the regional economics, the so-called gradient generally considers the situation of only one direction, and the mathematical expression is: Grad $\phi=\Delta \phi / \Delta \mathrm{S}$. The denominator $\phi$ generally refers to spatial distance of the regional studied on, and the molecular $\mathrm{S}$ stands for the hard or soft index of gradient phenomenon, including natural resources, GDP, the level of science and technology, industrial structure, the extent of population density and so on [1].

Gradient transfer theory gradually developed into the general gradient transfer theory. Not only take economic development as the common development of a number of economic, ecological and other indicators, but also take the regional economic development as a dynamic process. "Generally speaking, in the initial stage of economic development or backward industrialization, we should adopt the growth pole strategy; in the development which has certain foundation or in the middle stage of industrialization, we should adopt the point and axis development strategy; and in 
the better foundation of economic development or in the middle and later stage of industrialization, the strategic development network should be adopt. While the development of science and technology has broken the traditional industrial economy stage, then leading the society into a new stage of economic development, the space choice of the growth pole should be changed accordingly. When the implementation of growth pole development strategy in the backward areas, from a macro point of view, it is also a kind of anti-gradient development strategy. Growth pole, point axis diffusion and development of network these three kinds of theory and radiation theory in three aspects-point radiation, line radiation, and surface radiation-correspond [1]."

There are three kinds of effects present in gradient transfer, polarization effect (corresponding to the growth pole development strategy, but also leading to polarization, the rich richer, the poor poorer), diffusion effect (the driving and radiation effects from high gradient area to surrounding areas and low gradient areas), and backward effect (negative diffusion effect promotion, underdeveloped areas cannot digest capital, personnel and other resources from the high gradient area, resulting in the effect of resource flow).

Therefore, with the evolution of the cycle of economic development, and the proper use of promotion and transfer methods, the effect of gradient transfer process can be evolved. Usually, in the early stage of economic development, the polarization effect of developed regions and underdeveloped areas are the strongest; in the mature period of economic development, the diffusion effect is strongest; in the economic recession or transition period, when the net effect (= diffusion effect - backward effect) $>0$, the development of underdeveloped areas is still accelerating, and narrowing the gap between the regions, but when the net effect $<0$, the polarization effect is gradually increasing, and expanding gap between regions.

Lin Yifu uses "economic convergence" to describe the reduction of economic gap between developing and developed countries, and developing countries should choose the strategy of comparative advantage to develop their own economy, to achieve "economic convergence". Making full use of their comparative advantages, developing some preferential industries, introducing advanced technology, and following their own factor endowment structure. Economic growth accumulates economic surplus. With overall economic transformation and upgrading, and enterprise viability and endowment structure continuously optimized, in the "economic convergence", developing countries could constantly use dynamic changes of comparative advantage (freedom, openness, innovation, and technological progress...) to seek further development and even achieve "corner overtaking".

"The technical structure and optimal industry of an economy is decided by the factor endowment structure which is endogenous, and comparative advantage strategy is a better strategy for the less developed countries. This is because the comparative advantage strategy will induce less developed countries enterprises into industries with comparative advantages, and promote the enterprise to introduce advanced technology from more developed countries with low cost. The national economy will also have the competitive power. Factor endowment structure upgrades fast, and the upgrading of industrial and technological structure and will be relatively fast. Therefore, according to the comparative advantage strategy will help the underdeveloped countries convergence to developed countries...... in order to implement the strategy of comparative advantage, the government needs to maintain an open, free and competitive market, and the government can also use industrial policies to assist the enterprises in industrial and technological upgrading [2]."

\section{The Analysis of Comparative Advantage and Gradient Transfer Of Chinese Economy, AIIB and "the Belt and Road"}

From the domestic gradient transfer and the point of view of comparative advantage, "KeQiang index" composed of three indicators (the electricity consumption, rail freight volume and the amount of the loan) declined year by year, and GDP growth rate was $7.4 \%$ in 2014 . It also reflects Chinese economy comes into a "new normal". Excess capacity cannot be digested, and the transformation and upgrading speed of traditional industries is slow. Large energy consumption in the development of the extensive need to shift, and iron ore, coal and other bulk cargo transportation are affected; government begins to introduce a series of strategic planning and the "topdown design". "The Belt and Road", the Yangtze River economic belt, the establishment of new FTA, the integration Beijing Tianjin and Hebei, Bohai economic cooperation, the revitalization of the northeast, and a series of initiatives to achieve gradient transfer and diffusion effect from high gradient region to low gradient area, and there are comparative advantages of advanced technology and agglomeration economy to promote the coordinated development and regional economic integration and the use.

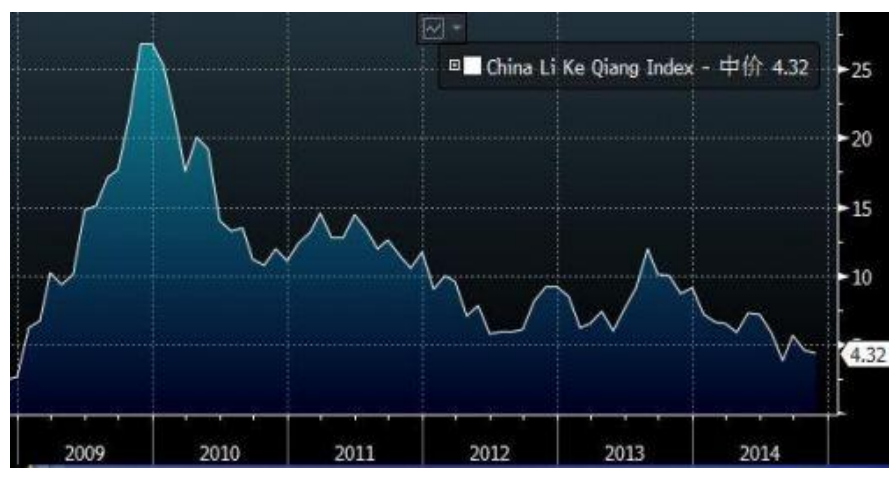

Fig. 1 China "KeQiang Index" (2009-2014)

Source: wallstreetcn.com

From the view of external environment, with the rapid growth of the Asian economy over the past few decades, first emerged in Japan (the second largest economy in the world), and then the "four little dragons" of Asia (Singapore, 
HongKong, Korea, and Taiwan) followed. Due to the Asian economic crisis, Asia's growth pole is reflected in the "China miracle". In recent years, with the loss of gradient transfer and comparative advantage to a certain extent, South Asia (India) is rapidly rising, and even a lot of industries move from China to ASEAN countries and other developing countries; in the economic system and organization structure dominated by developed countries; American, Japan and other allies and countries began to promote the TPP (Trans -Pacific Partnership) and TTIP (Transatlantic Trade and Investment Partnership). The same points are to establish small organizations like WTO, the tariff between the members of the organization of is very low even for 0 , most countries covering the Asia Pacific region and the Atlantic region, and excluding China the second largest economy in the world trade organization. The establishment and development of the two trade organization and the frustration and delay of RMB join SDR, to a certain extent, marks the decline of postwar WTO trading system and the economic systems led by American and some developed countries contain the development of China.

In the past the focus of reform and opening-up is the priority to the east development and opening of coastal city. The western development strategy is practical application of gradient theory in the beginning of 21 st Century in China, but now it seems the polarization effect is obvious, and the gap between eastern and western regions in the regional economic development expanded. In the past Chinese economy made full use of comparative advantage to achieve the rapid development, and became the world's second largest economy. But with the economic downturn, economic issues emerged, increasing overcapacity, super currency, high labour costs, environmental problems and so on, the past comparative advantage is no longer obvious, and the advantages gradually transform into disadvantages. In the "new normal", in order to further develop the new comparative advantages, to achieve suitable gradient transfer, maintain steady economic growth, the breakthrough which China has found is AIIB and "the Belt and Road", also the new reform and opening-up and the "topdown design" under the background of Chinese economic new normal "

As a new regional financial institutions AIIB is proposed and created by China, and its main business is the construction of infrastructure to help Asian countries and developing countries. President Xi Jinping visited Indonesia in 2013 was first proposed to build Chinese initiative, willing to help Indonesia and other ASEAN countries to develop the infrastructure construction. In October 24, 2014, China, Singapore, India, the first 21 members signed the agreement of intent, in March 12, 2015, Britain became the first to apply, apply to join the western developed countries, then all developed countries, developing countries and important economies have also added. By the end of April 15th, the investment bank in the 57 founding members of the intention, countries within the 37, 20 foreign countries, a time to become the most fashionable inter-governmental multilateral financial institutions, and it does not exclude countries as ordinary members, will continue to expand the scale.

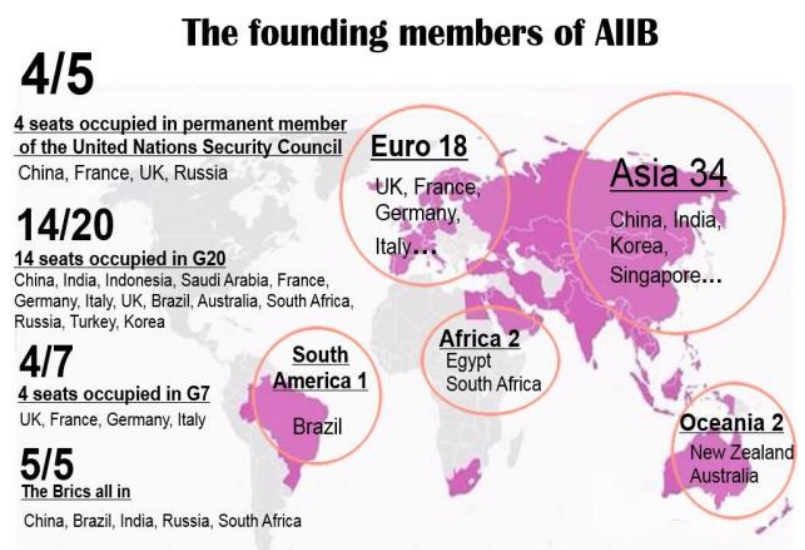

Fig. 2 The founding members of AIIB

AIIB is an effective supplement to World Bank and Asian Development Bank, which makes up for the lack of funds for infrastructure construction. China has a further leading financial institutions in the following of New Development Bank, to increase its own influence in the world economy and finance. The concept of win-win cooperation put forward by China has also been recognized by many countries, and the key is to common profit and common development. AIIB makes full use of China's huge foreign exchange reserves and domestic savings (China's capital output), to cooperation with other countries for national economic development, mutual benefit and reciprocity.

There is old Silk Road in the ancient China, and the construction of "Eurasian Continental Bridge" in 80's and 90's of last century.

When Chinese President Xi Jinping visited Central Asia and Southeast Asia in September and October of 2013, he raised the initiative of jointly building the Silk Road Economic Belt and the 21st-Century Maritime Silk Road (hereinafter referred to as the Belt and Road), which have attracted close attention from all over the world. At the China-ASEAN Expo in 2013, Chinese Premier Li Keqiang emphasized the need to build the Maritime Silk Road oriented towards ASEAN, and to create strategic propellers for hinterland development. Accelerating the building of the Belt and Road can help promote the economic prosperity of the countries along the Belt and Road and regional economic cooperation, strengthen exchanges and mutual learning between different civilizations, and promote world peace and development. It is a great undertaking that will benefit people around the world. The Belt and Road Initiative is a systematic project, which should be jointly built through consultation to meet the interests of all, and efforts should be made to integrate the development strategies of the countries along the Belt and Road. The Chinese government has drafted and published the Vision and Actions on Jointly Building Silk Road Economic Belt and 21st-Century Maritime Silk Road to promote the 
implementation of the Initiative, instill vigor and vitality into the ancient Silk Road, connect Asian, European and African countries more closely and promote mutually beneficial cooperation to a new high and in new forms [3].

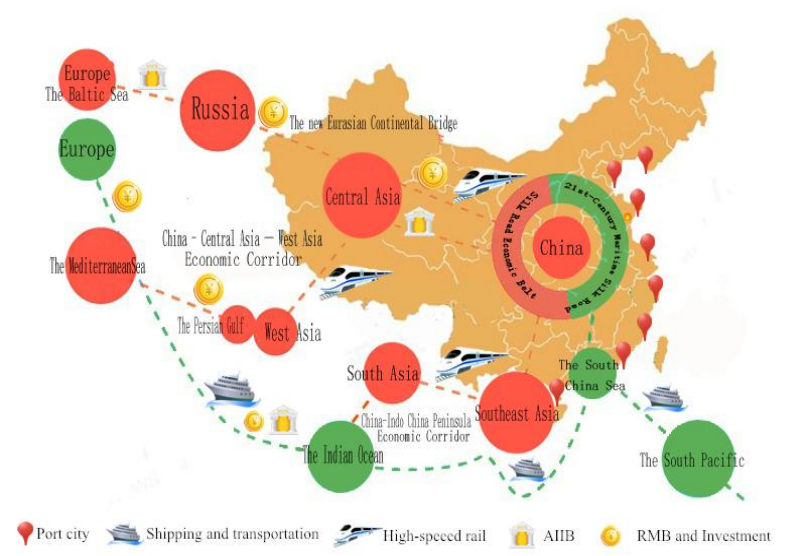

Fig. 3 The Belt and Road (One Belt and One Road)

In terms of comparative advantage, through AIIB and "the Belt and Road", Chinese excess high-quality capacity can be output abroad. Apart from the elimination of backward production capacity, Chinese construction quality, efficiency, cost and other aspects have competitiveness in the world, including "low cost, high quality" of transportation and Highspeed Rail construction; AIIB and the Silk Road transfer the Chinese fund reserves and internal savings into strategic investments in the developing world, greatly raising the income level, and China through their own economic strength and capital output accumulated for 30 years, promote the allround output of technology, product, service, equipment and so on, and stimulate the potential energy, resources and other advantages of developing countries through the construction of infrastructure, and evolve them into tangible benefits, and realize a win-win situation with developing countries.

In terms of gradient transfer, from the angle of reform and opening-up, many provinces and cities of domestic eastern, central, and western areas are involved. There is some gradient transfer and diffusion effects in internal roughly in line with the direction of "eastern $\rightarrow$ central $\rightarrow$ western"; while there is foreign gradient transfer in the eastern economic areas, such as the creation of Shanghai Free Trade Zone, Fujian as a core area of the Maritime Silk Road. And there is foreign gradient transfer from central and west to West Asia and Europe, such as building Xinjiang as the core zone of Silk Road Belt, and promoting border trade and tourism and cultural cooperation between Tibet and other countries such as Nepal etc. In the past the central and western underdeveloped areas is the end of the reform and opening-up and low gradient areas. In the new strategic framework of "the Belt and Road", these regions and eastern regions are the same as the forefront of the new reform and opening-up. The traditional eastern regions emphasis on "21st Century Maritime Silk Road" more, and the central and western regions emphasis on "the New Silk Road Economic Zone" more. But in fact, the two intersect each other and gradient transfer mutually. In the framework of "the Belt and Road", there are 4 large regions (the northeast and northwest regions, southwest region, inland regions, and coastal areas, Hong Kong, Macao and Taiwan) all-round opening different from traditional east, middle and west areas.

Countries along the Belt and Road have their own resource advantages and their economies are mutually complementary. Therefore, there is a great potential and space for cooperation. They should promote policy coordination, facilities connectivity, unimpeded trade, financial integration and people-to-people bonds as their five major goals, and strengthen cooperation [3].

\section{Conclusion}

Compared with the traditional regional bank, AIIB is an effective supplement to World Bank and Asian Development Bank, and China has a further leading financial institutions in the following of New Development Bank to increase its own influence in the world economy and finance. AIIB makes full use of China's huge foreign exchange reserves and domestic savings (China's capital output), to cooperation with other countries for national economic development, mutual benefit and reciprocity. In advancing the Belt and Road Initiative, China will fully leverage the comparative advantages of its various regions, adopt a proactive strategy of further openingup, strengthen interaction and cooperation among the eastern, western and central regions, and comprehensively improve the openness of the Chinese economy.

The findings could be helpful to understand the impact of AIIB and "the Belt and Road", as the new reform and openingup "top-down design" under the background of Chinese economic "new normal", Chinese gradient transfer and comparative advantages.

Chinese new gradient transfer and comparative advantages with AIIB, "the Belt and Road" and other strategies, which will help China to go through the "new normal" stably, across the middle income trap, become one of the most powerful and innovative countries, and achieve common development with other countries in the world, are the new Reform and Opening-up and "Top-down Design" under the background of economic "New Normal".

\section{References}

[1] Li Guoping, and $\mathrm{Xu}$ Yang, "The development and significance of gradient theory," Economists, voL 4, pp.69-75, 2002.

[2] Justin Yifu Lin, "Development Strategy, Viability and Economic Covergency", China Economic Quarterly, voL 1, no. 2, pp.269-300, January 2002.

[3] National Development and Reform Commission, Ministry of Foreign Affairs, and Ministry of Commerce of the People's Republic of China, "Vision and Actions on Jointly Building Silk Road Economic Belt and 21st-Century Maritime Silk Road," People’s Education Press.2015. 